Volume: 11 Issue: 1 Year: 2014

\title{
Physical activity participation related challenges that adolescent Montagnard refugee youth encounter in America
}

\author{
Jerono P. Rotich ${ }^{1}$
}

\begin{abstract}
Although research has identified that physical activity enhances the psychosocial, physiological, and the academic well-being of at-risk youth, little information is known about the unique challenges that adolescent Montagnard refugee youth face as they acculturate into the United States of America.

Methods: This case study used photovoice methodology (Wang, 1998) to examine the physical activity participation related challenges that adolescent Montagnard immigrant youth encounter upon arrival into the United Stated of America. Sixteen adolescent Montagnard youth (eight male and eight female) participated in this intensive study. They all completed a demographic survey with the use of two bilingual and bicultural interpreters (1 male and 1 female), participated in photovoice training on the use of cameras, took photographs, wrote photo captions, and shared stories about their pictures. A total 356 photographs were developed and analyzed.

Results: The results from the photovoice study clearly indicated that the environmental, sociocultural, and socio-demographic were the main barriers to participating in physical activity as well as accessing community parks and recreation amenities.

Conclusion: The findings reaffirmed that collaborations among all stakeholders were invaluable, especially in cross-cultural settings.
\end{abstract}

Keywords: Montagnard; Immigrant Youth; Youth Physical Activity; Acculturation

\section{Introduction}

The Montagnard People: The term Montagnard pronounced "mountain yard" is also known as "Dega." It is a French word, which means "Mountain people (Kaleidoscope, 2003). According to the Kaleidoscope, the Montagnards are one of the oldest indigenous people of Southeast Asia. Although they lived in the central highlands of South Vietnam for over 2000 years,

\footnotetext{
${ }^{1}$ Assoc. Prof., North Carolina Agricultural \& Technical State University, Department of Human Performance and Leisure Studies, USA, jprotich@ncat.edu
} 
Rotich, J. P. (2014). Physical activity participation related challenges that adolescent Montagnard refugee youth encounter in America. International Journal of Human Sciences, 11(1), 45-54. doi: 10.14687/ijhs.v11i1.2734

their language and culture is remarkably different from that of the Vietnamese. They are comprised of different tribes, with many overlapping customs, lifestyles, and language patterns. Their distinct languages can be traced to the Mon-Khmer and the Malayo-Polynesian language groups. They specifically identify themselves by their languages and place of origin. The main tribes, in order of population size and location are listed as follows: 1) Jarai - North West part of Vietnam and number over 300,000; 2) Rhade- Western part of Vietnam and are over 250,000; 3) Bahnar North Eastern part of Vietnam and are over 180,000; 4) Koho- Southern part of Vietnam and are over 120,000, and 5) Mnong -South Western part of Vietnam and are over 85,000.

Anecdotal evidence from the International Montagnard Bible Church indicates that, although the Montagnard people are culturally and linguistically remarkably different from the Vietnamese, some were forced to learn Vietnamese as they attended Vietnamese schools. Although the United States and North Carolina continue to witness a massive influx of immigrants, statistics from North Carolina indicate that the Montagnard group represents the largest population outside of Vietnam (Kaleidoscope, 2003 \& Bailey, 2002).

Perceived Determinants of Physical Activity: Several researchers (Sallis, 1993; Trost, Pate, Saunders, Ward, Dowda, \& Felton, 1997; Gordon-Lasen, et al, 2000) have documented determinants of physical activity. These studies suggest that demographic, psychosocial, and environmental factors are key determinants that are known to affect the physical activity participation among children and adolescents. They state that the demographic factors include gender, age, and race or ethnicity. They also reveal the fact that: girls are less active than boys are, and older children and adolescents are less active than younger children and adolescents.

In reference to the individual determinants, domains such as confidence and self-efficacy in one's ability to engage in sports have been of considerable influence (Trost, Pate, Dowda, Saunders, Ward, \& Felton, 1997). Other individual determinants domains that have been mentioned include; adolescent's perceptions of physical activity (Biddle \& Goudas 1996), their attitudes toward physical, and relaxation or entertainment that they gain from participation (Stucky-Ropp \&, DiLorenzo 1993). Their findings suggest that some kids will only participate in physical activity if they have an understanding of the benefits of engagement. Additionally, the individual's readiness for change or stage of change is reported to be another significant barrier (Marcus, \& Forsyth, 2003). They emphasize that the stages of change are crucial because they affect the progress and maintenance of physical activity. 
Rotich, J. P. (2014). Physical activity participation related challenges that adolescent Montagnard refugee youth encounter in America. International Journal of Human Sciences, 11(1), 45-54. doi: 10.14687/ijhs.v11i1.2734

Research has also alluded to some determinants of participation in physical activity (StuckyRopp \&, DiLorenzo, 1993; Andersen \& Wold, 1992; Biddle \& Goudas 1996). Their findings suggest that lack of time, environmental and interpersonal factors had an impact on participation in physical activity among most youth. Parental support and encouragement has also been reported (Biddle \& Goudas 1996). Findings from the US Department of Health and Human Services, Surgeon General Report (1996) also support the parental concept. They suggested that parents who participated in physical activity had a tremendous influence on the activity levels of their children. In addition, the reports indicated that older children and adolescents who had friends who are physically active had a tendency to be physically active. Younger children (up to age 12) mentioned family members as their most popular activity partners and supporters.

Other determinants that have been mentioned include access to appropriate play spaces or facilities, availability of physical activity equipment, facilities, and transportation to sports programs (Stucky-Ropp \& DiLorenzo, 1993). Social economic status has had significant influences on physical activity participation (Lox et al, 2003). Specific data from the United States indicated that lower income individuals were less likely $(14 \%)$ to engage in vigorous physical activity than the entire US population (18\%) (Lox et al, 2003). Additional information from this report indicated that lower income individuals were more sedentary (28\%), when compared with the overall population $(23 \%)$.

Although several research studies have been conducted on the determinants of physical activity among youth, most studies have focused on the mainstream American youth. It is also clear that a limited amount of research has been done to uncover the determinants of physical inactivity among different Montagnard refugee youth. To address the gaps in the research literature, this case study focused on identifying the physical activity participation challenges that adolescent Montagnard refugee youth encountered upon arrival to the United States of America.

\section{Methodology}

The participants for this research study were sixteen adolescent Montagnard immigrant youth between the ages of 12-17 ( 8 male and 8 female). The sixteen youth were recruited based on the following criteria: (1) adolescent Montagnard immigrant youth aged 12-17 years, (2) resident of Guilford County, North Carolina, (3) and had lived in the United States for less than 5 years. A total of ten participants reported that they had lived in the United States of America for less than four years ( 6 male and 4 female), and the remaining six ( 2 male and 4 female) reported that they had 
Rotich, J. P. (2014). Physical activity participation related challenges that adolescent Montagnard refugee youth encounter in America. International Journal of Human Sciences, 11(1), 45-54. doi: 10.14687/ijhs.v11i1.2734

lived in the United States of America for four years. They were in middle $(\mathrm{n}=10)$ and high school $(\mathrm{n}=6)$, and they spoke four different languages (Rhade, Koho, jarai \& Bnong). The participants were all selected from Guilford County and Greensboro in particular because the City has the largest number of Montagnard refugees in the world outside of Vietnam (Bailey 2003).

Participant Selection: As alluded to above, criterion- based sampling (Goetz \& LeCompte, 1984) was used to determine the participants for this study. The researcher used two trained bicultural and bilingual Montagnard Lay Health Advisors (1 male and 1 female) to recommend and recruit a convenient sample based on the set criteria. They used snowball or chain sampling to determine the well-suited youth from the Montagnard Community. To ensure effective communication and respect of gender issues during this process, a trained bilingual and a bicultural male and female interpreter/translator were utilized. They recommended and contacted a chain of individual youth who would be good sources of information and youth who would make a commitment to complete the three-month study. The interpreters were able to consult and receive a recommendation of names from a wide population of the Montagnards because they spoke different languages. The female interpreter spoke four languages (Rhade, Jarai, Koho, and Vietnamese), and the male interpreter spoke five languages (Rhade, Jarai, Bnong, Koho, and Vietnamese). After the final sixteen ( 8 male and 8 female) were identified, the researcher and research assistants met with each one of the youth and their guardians or parents to further explain the study, to define the level of commitment that was required, to answers any of their questions, and to obtain verbal permission as indicated in the institutional review board. The youth were reminded that it was necessary for them to complete the investigation and that they would continue to keep the cameras, and the colored pencils, and pens that they used for writing the photo captions.

Research Design: The photovoice methodology (Wang, 1998) was used to collect data for this study. However, minor modifications were made in order to accommodate the unique acculturation needs of the Montagnard youth and their families. Photovoice is designed to empower the marginalized or disenfranchised members of any given community and to influence policy makers for social change (Wang, 1998). Several researchers who have utilized this methodology (Killion, C.M., \& Wang, C.C.2000; Wang, \& Redwood-Jones, 2001; Wang, Cash, \& Powers, 2000), have described it as a very helpful and innovative participatory needs assessment and evaluation tool. Specifically, this method was deemed useful for this study because it can be used effectively with communities who may have language disparities that tend to limit their ability to respond to either survey questionnaires or structured interviews. Through the use of cameras, 
Rotich, J. P. (2014). Physical activity participation related challenges that adolescent Montagnard refugee youth encounter in America. International Journal of Human Sciences, 11(1), 45-54. doi: 10.14687/ijhs.v11i1.2734

the youth took pictures and met regularly to write captions and share and discuss stories about their photographs. These captions and discussions focused on physical activity participation challenges and factors that could put them at risk of being overweight as they acculturate into their new culture and environment. The procedures of the study were based on five progressive tiers. These tiers outline specific procedures such as collecting demographic information, photovoice training, data collection, and data analysis. The following table (Table 1) gives an overview of the components of each tier. Specifically it gives information on what the tier consisted of, how it was be implemented, and why it was necessary.

Table 1: Components and Purposes for Each the Tiers

\begin{tabular}{|c|c|c|c|}
\hline Tier & What & How & Why \\
\hline$\underline{1}$ & $\begin{array}{l}\text { Collected } \\
\text { demographic } \\
\text { information }\end{array}$ & $\begin{array}{l}16 \text { adolescent Montagnard immigrant youth ages } 12 \text { - } \\
17 \text { years were randomly identified ( } 8 \text { male and } 8 \\
\text { female) }\end{array}$ & $\begin{array}{l}\text { To obtain demographic } \\
\text { information }\end{array}$ \\
\hline$\underline{2}$ & $\begin{array}{l}\text { Photovoice } \\
\text { preparation and } \\
\text { distribution of } \\
\text { cameras and films }\end{array}$ & $\begin{array}{l}\text { Participants met with researcher for } 2-3 \text { hours to } \\
\text { talk about photovoice methodology, the goals and } \\
\text { objectives of the study }\end{array}$ & $\begin{array}{l}\text { To train participants on the } \\
\text { methodology, goals and } \\
\text { objectives of the study }\end{array}$ \\
\hline$\underline{3}$ & $\begin{array}{l}\text { Took photos } \\
\text { /collected data }\end{array}$ & $\begin{array}{l}\text { The following was the specific problem that was } \\
\text { addressed. } \\
\text { What barriers do adolescent Montagnard immigrant } \\
\text { youth encounter as they make efforts to participate } \\
\text { in physical activity? }\end{array}$ & $\begin{array}{l}\text { To collect data and } \\
\text { information on physical } \\
\text { activity } \\
\text { challenges }\end{array}$ \\
\hline 4 & $\begin{array}{l}\text { Selected } \\
\text { photographs and } \\
\text { conceptualize } \\
\text { stories }\end{array}$ & $\begin{array}{l}\text { Individual and group meeting to discuss pictures, } \\
\text { share stories and write captions about their } \\
\text { photographs }\end{array}$ & $\begin{array}{l}\text { To analyze and code data to } \\
\text { identify recurring activities, } \\
\text { themes and ideas }\end{array}$ \\
\hline$\underline{5}$ & $\begin{array}{l}\text { Codified activities } \\
\text { and themes }\end{array}$ & $\begin{array}{l}\text { The youth met, and codified the activities and } \\
\text { themes }\end{array}$ & $\begin{array}{l}\text { To categorize themes and } \\
\text { activities }\end{array}$ \\
\hline
\end{tabular}

\section{Results and Discussions}

These data findings provided valuable information regarding the challenges that adolescent Montagnard refugee youth encountered upon arrival to the United States of America. The findings indicated that although the youth participated in a diverse repertoire of physical activities, they 
Rotich, J. P. (2014). Physical activity participation related challenges that adolescent Montagnard refugee youth encounter in America. International Joumal of Human Sciences, 11(1), 45-54. doi: 10.14687/ijhs.v11i1.2734

encountered numerous challenges. The barriers/challenges were categorized into the following three categories; 1) environmental; 2) sociocultural; and 3) socio-demographic.

\section{Environmental Barriers}

Environmental barriers were described as gloomy factors that emerged from the environment. The findings from this study clearly indicated that environmental barriers emerged as major challenges of participation in physical activity among the adolescent Montagnard immigrant youth.

As the youth illustrated in their photographs, the environment in which the Montagnard families settled provided great barriers. They did not have access to physical activity facilities and equipment. Other specific barriers included lack of adequate transportation, limited sidewalks, overcrowded neighborhood, lack of neighborhood playgrounds and sidewalks. They also noted that most of their apartments were within close proximity to vast moving traffic. Neighborhood related violent crimes also emerged as significant barrier to outdoor physical activity during nonschool hours.

As indicated by previous reports (Portes \& Rumbant, 1996; Bailey, 2002), most Montagnards (just like other immigrants) had limited options on where they settled during their first years of arrival. Due to financial struggles, they settled in isolated ethnic enclaves in low socioeconomic neighborhoods, which are characterized by the various environmental barriers. Some of these findings were also consistent with that of Gordon (2003), which pointed out that, neighborhood crime level is significantly associated with a decline in weekly participation of moderate to vigorous physical activity.

The youth also reported that they lived in apartments, which were not within close proximity to community parks and recreation. In addition, as noted earlier, most of the youth and their families do not have reliable means of transportation. This observation is consistent with findings reported by Gordon (2003). His study suggested that, living in close proximity to a community recreation center was associated with an increased likelihood of engaging in high-level moderate to vigorous physical activity.

Sociocultural Barriers: Other physical activity challenges that were reported by the youth were those that emanated from socio-cultural contexts of the Montagnard people. As indicated previously, the cultural background and beliefs of the Montagnards do not endorse nor give a 
Rotich, J. P. (2014). Physical activity participation related challenges that adolescent Montagnard refugee youth encounter in America. International Joumal of Human Sciences, 11(1), 45-54. doi: 10.14687/ijhs.v11i1.2734

preference to participation in physical activity, especially for the females. According to earlier reports (Bailey, 2002), it is clear that when the adolescent Montagnard immigrant youth left Vietnam, they left behind their everyday language, culture, people and lifestyles. The youth indicated that some of their long-held customs, and beliefs, values and practices conflicted with "what America expects" of them. They specifically pointed out the fact that among the Montagnards, physical activity is viewed as a men's activity and more so as a means of transportation.

Thus, most youth reported that their families were least supportive when it came to participation in physical activity. They acknowledged that they did not participate in the recommended levels physical activity most of the days of the week because they lacked positive role models. They specifically pointed out that they lacked parental and peer support. Possible reasons for this lack of support are attributed to misconceptions and minimal understanding of the significance of participation in physical activity. The females in particular described instances in which family members prompted them to stop participating in physical activity because of the perceptions that physical activity would make females look either skinny or too masculine.

The Montagnard culture encouraged girls to stay home and take care of siblings and household chores. Boys or males on the other hand are seen as breadwinners therefore are expected to be outdoors. They also pointed out that, according to most of their cultures, it is forbidden for males to be seen working or helping in the kitchen. In regards to peer support, the youth reported that they had limited friends and peers who could motivate them to participate in physical activity. They argued that because they lived in segregated neighborhoods, most of their friends and neighbors were from their country and culture, so they do not encourage each because they experienced similar challenges. Overall, it was noted that as the youth described their sociocultural barriers to participation, females were more likely to identify parents as major obstacles, but the males were more likely to identify peers.

The difference in modes of entertainment among the Montagnards and American community is also reported to contribute to the low levels of participation. The youth reported that the American society of advanced technology contributed to lifestyles that are more sedentary. They pointed out that the multitude of electronic entertainment such as television, video games, and computers occupied most of the youths' non-school time thus contributing to less physical activity. The youth reported that, due to poor technology in the mountains and jungles of Vietnam, they were forced by circumstances to spend all their free time playing outdoors with friends. 
Rotich, J. P. (2014). Physical activity participation related challenges that adolescent Montagnard refugee youth encounter in America. International Journal of Human Sciences, 11(1), 45-54. doi: 10.14687/ijhs.v11i1.2734

Socio-demographic Barriers: The youth emphasized the fact that, due to acculturation and immigration challenges (i.e. financial disadvantages, language barriers, limited education, posttraumatic stress, family separation, and transformation of individual roles); they did not have complete control over how they spent their out of school time or leisure time. These findings are consistent with the Surgeon General's Report (CDC, 2002), which pointed out that most individuals do not have complete control of how they spend their leisure time.

Specific findings from this study showed that all the youth who participated in this study lived in families that had significantly lower incomes. Consequently, these financial strains among other struggles forced them to settle in low socio-economic neighborhoods with limited access to public transportation among others as indicated in previous reports (Bailey, 2003; Portes \& Rumbaut, 1996; Maat, 1997). The youth also indicated that as much as they wanted to learn how to play American sports such as tennis, soccer, and basketball, financial strains made it impossible for them and their families to afford memberships to places where such opportunities would be available. Their parents could not afford membership to YMCA or YWCA, and could not provide transportation to physical activity venues or programs. These findings are consistent with findings by Gordon (2003), which pointed that income levels are believed to affect the level of participation in physical activity. This explains why most of youth indicated that they were keen to see their parents learn English, get better paying jobs so that they get their own cars.

Other potential barriers included the massive immigration and acculturation challenges (Portes \& Rumbant, 1996; Bailey, 2002). It was obvious that though most Montagnards see America as beacon of hope and freedom, jobs and opportunities to better their lives and that of their children remain a priority. As a result, most parents are forced to pick up more than one job, thus leaving the youth with lots of responsibilities at home and no leisure time to engage in physical activity.

Additional findings suggested that adolescent Montagnard immigrant youth were verbally excluded from participation in physical activity. The youth acknowledged that they encountered numerous language barriers. The youth reported that there was no written texts material (i.e. brochures, flyers, forms) that was available in any of their five languages (Coho, Bnong, Jarai, Rhade, and Vietnamese). As a result, neither they nor their families get any information on any of the available resources in their community or schools. The youth further argued that this lack of information is associated with the lack of parental support. Notably, many of these immigrant parents do not encourage participation in physical activity due to limited knowledge on the 
Rotich, J. P. (2014). Physical activity participation related challenges that adolescent Montagnard refugee youth encounter in America. International Journal of Human Sciences, 11(1), 45-54. doi: 10.14687/ijhs.v11i1.2734

importance of participation. Most of the parents do not speak English and have undergone very few years of formal education. This is consistent with findings by Gordon (2003), which indicated that maternal education was inversely associated with high inactivity patterns. Gordon indicated that mothers who had college degrees were more likely to encourage their children to participate in physical activity.

\section{Conclusion}

Overall, the findings on the challenges of participation in physical activity reinforce the findings from previous studies that examined determinants of physical activity (Adams, Schoenborn, Moss, Warren, \& Kann, 1992; CDC, 1995; Sallis, 1993; Gordon 2003). Though this study confirms the importance of environmental determinants, it unveiled further in-depth information on the sociocultural and socio-demographic challenges among adolescent Montagnard immigrant youth. In conclusion, the findings reaffirmed that collaborations among all stakeholders were invaluable, especially in cross-cultural settings.

\section{References}

Adams, P. F., Schoenborn, C. A., Moss, A. J., Warren, C.W., Kann, L. (1992). Health-risk bebaviors among our nation's youth: United States, (PHS 95-1520, Vital and Health Statistics Series 10, Data from the National Health Interview Survey, No. 192). Hyattsville, MD: Centers for Disease Control and Prevention, National Center for Health Statistics

Anderssen, N., Wold, B. (1992). Parental and peer influences on leisure-time physical activity in young adolescents. Research Quarterly for Exercise and Sport, 63(4), 341348.

Bailey, R. (2003). Center for New North Carolinians: Immigrant Health ACCESS

Bailey, R. (2002). Demographics of immigrants in Guilford County, NC. \{Report posted on the Web\}. Retrieved December 10, 2012 from the CNNC web: http://cnnc.uncg.edu/information/pop_demgraphics.html

Biddle, S., Goudas, M. (1996). Analysis of children's physical activity and its association with adult encouragement and social cognitive variables. Journal of School Health, 66(2): 75-8.

Collingwood, T.R. (1997). Helping at-risk youth through physical fitness programming. IL: Human Kinetics.

Goetz, J.E., LeCompte, M.D (1994). Ethnography and qualitative design in Educational Research. Orlando, FL: Academic Press.

Gordon-Larsen, P., McMurra, G.R., Popkin, M.B. (2000). Determinants of adolescent physical activity and inactivity patterns. Pediatrics 105 (6) 83-105.

Lox, C., Martin, K., Petruzzello, S. (2003).The psychology of exercise: integrating theory and practice. Scottsdale, Ariz; Holcomb Hathaway Publishers.

Kaleidoscope, (2003). Cultural Diversity in Guilford County. A training handbook for Health and human service providers.

Killion, C.M., Wang, C.C. (2000). Linking African American mothers across life stage and station through photovoice. Journal of Health Care for the Poor and Underserved, 11 (3), 310-325.

Maat, M.B. (1997). A group art therapy experience for immigrant adolescents. American Journal of Arts Therapy, 36:11-19. 
Rotich, J. P. (2014). Physical activity participation related challenges that adolescent Montagnard refugee youth encounter in America. International Journal of Human Sciences, 11(1), 45-54. doi: 10.14687/ijhs.v11i1.2734

Marcus, H.B., Forsyth, H. L. (2003). Motivating people to be physically active. Champaign, IL; Human Kinetics.

Portes, A., Rumbaut, R.G. (1996). Immigrant America, Berkeley, CA: University of California -Press.

Sallis, J.F., Patrick, K. (1994). Physical activity guidelines for adolescents: consensus statement. Pediatric Exercise Science, 6:302-314.

Sallis, J.F. (1993). Epidemiology of physical activity and fitness in children and adolescents. Food Science Nutrition, 33 (4/5): 403-408.

Stucky-Ropp, R.C., DiLorenzo, T. M. (1993). Determinants of exercise in children. Preventive Medicine, 22, 880-889.

Trost, S.G., Pate, R.R., Saunders, R., Ward, D.S., Dowda, M. Felton, G. A. (1997). A prospective study of determinants of physical activity in rural fifth grade children. Preventive Med, 26:257263.

US Department of Health and Human Services (1996). Physical activity and health: A report of the surgeon general. Atlanta, GA: US Department of Health and Human Services, Centers for Disease Control and Prevention, National Center for Chronic Disease Prevention and Health Promotion.

Wang, C.C., Cash, J.L., Powers, L.S. (2000). Who knows the streets as well as the homeless? Promoting personal and community action through photovoice. Health Promotion Practice, 1: 81-89, 2000.

Wang, C., Redwood-Jones, Y. (October 2001). Photovoice ethics: Perspectives from flint photovoice. Health Education, 28(5): 560-572.

Wang, C.C. (1998). Involving homeless men and women of Washtenaw county, Michigan. Health Education and Behavior, 25 (1): 9-10. 